\title{
TLR4 as receptor for HMGB1-mediated acute lung injury after liver ischemia/reperfusion injury
}

\author{
Zhongwei Yang, Yuxiao Deng, Diansan Su, Jie Tian, Yuan Gao, Zhengyu He and Xiangrui Wang
}

Acute lung injury (ALI) frequently occurs after liver transplantation and major liver surgery. Proinflammatory mediators released by damaged liver after liver ischemia/reperfusion (I/R) injury might contribute to this form of ALI, but the underlying mechanisms have not been well characterized. High-mobility group box protein 1 (HMGB1), a recently identified proinflammatory cytokine, was found to be significantly higher in the serum after liver I/R injury. This study investigated whether HMGB1 was involved as a stimulating factor, and whether its downstream Toll-like receptor 4 (TLR4), p38 mitogen-activated protein kinase (p38MAPK), and activator protein-1 (AP-1) signaling pathways act as mediators in the development of liver I/R injury-induced ALI. Extensive ALI and lung inflammation was induced in a rat model of liver I/R injury. Serum HMGB1 was significantly higher after liver I/R injury, and more importantly, expression of HMGB1 mRNA and protein in the lung tissue was also significantly increased. We further found that liver I/R injury enhanced the expression of TLR4 mRNA and protein, and the activity of p38MAPK and AP-1 in the lung tissue. Inhibition of TLR4 expression in the lung tissue by infection with pGCSIL-GFP-lentivirus-expressing small hairpin RNAs targeting the TLR4 gene (TLR4-shRNA lentivirus) significantly attenuated ALI, lung inflammation, and activity of p38MAPK and AP-1 in the lung tissue. These findings indicate that HMGB1 might contribute to the underlying mechanism for liver I/R injuryinduced ALI and that its downstream TLR4, P38MAPK, and AP-1 signaling pathways are potentially important mediators in the development of ALI.

Laboratory Investigation (2013) 93, 792-800; doi:10.1038/labinvest.2013.66; published online 29 April 2013

KEYWORDS: acute lung injury; AP-1; HMGB1; liver I/R Injury; P38MAPK; TLR4

Acute lung injury (ALI) and its more severe form, the acute respiratory distress syndrome (ARDS), are common complications of liver transplantation and major liver surgery, and thereby significantly contributed to perioperative morbidity and mortality. ${ }^{1,2}$ Liver I/R injury may account for this form of ALI, but the underlying mechanisms have not been fully elucidated. Since the lungs are the first capillary bed that is reached by the blood after leaving the hepatic circulation, one proposed mechanism is that ALI may be induced by proinflammatory mediators released from the injured liver into system circulation. ${ }^{3-7}$

High-mobility group box protein 1 (HMGB1), originally identified as a DNA-binding protein, is a proximal trigger that is sufficient to induce the release of other cytokines classically associated with mediating inflammatory responses, including tumor necrosis factor- $\alpha$ (TNF- $\alpha$ ), interleukin- $1 \beta$ (IL-1 $\beta$ ), and interleukin-6 (IL-6). ${ }^{8}$ Interestingly, HMGB1 was rapidly mobilized and released into system circulation by hepatocytes in the setting of liver I/R injury. ${ }^{8,9}$ HMGB1 has also been reported to participate in ALI and lung inflammatory response induced by endotoxin, ventilator, and hemorrhage. ${ }^{10-12}$ For example, HMGB1 expression in the lung was found to be increased within $4 \mathrm{~h}$ of hemorrhage, and then remained elevated for more than $72 \mathrm{~h}$ after blood loss. Blockade of HMGB1 by the administration of neutralizing antibodies prevented hemorrhage-induced increases in pulmonary levels of proinflammatory cytokines, including keratinocyte-derived chemokine, IL-6, and IL- $1 \beta .{ }^{11}$ However, whether HMGB1 participated in liver I/R injuryinduced ALI is still unclear.

Extracellular HMGB1 functions as a damage-associated molecular pattern molecule and activates proinflammatory signaling pathways by activating pattern recognition receptors, including Toll-like receptor 4 (TLR4) and the receptor for advanced glycation end-products (RAGE) ${ }^{13,14}$. While RAGE has only a minor role in macrophage activation 
by HMGB1, the triggering of the TLR4 signaling pathway by HMGB1 leads to the activation of p38 mitogen-activated protein kinase ( $\mathrm{p} 38 \mathrm{MAPK})$ through the accessory protein MyD88, which subsequently activates activator protein-1 (AP-1), and thus regulates inflammatory cytokine expression. ${ }^{15,16}$ Excessive cytokine-mediated inflammation has a fundamental role in the pathogenesis of ALI. ${ }^{17,18}$ In addition, TLR4 is widely distributed in alveolar and bronchial epithelial and vascular endothelial cells in the lung. ${ }^{19-21} \mathrm{We}$ have previously demonstrated that the activation of TLR4 and its downstream intracellular signal-transduction pathways is crucial to lipopolysaccharide (LPS)-induced ALI. ${ }^{22-24}$ Other studies also reported that TLR4 mutant $(\mathrm{C} 3 \mathrm{H} / \mathrm{HeJ})$ mice developed less ALI after unresuscitated hemorrhagic shock or being challenged with LPS. ${ }^{25,26}$ Conversely, the overexpression of TLR4 in transgenic mice aggravated ALI and pulmonary inflammation, endothelial cell damage, and the recruitment of neutrophils to the lung. ${ }^{27}$ The HMGB1-TLR4 signaling pathway has been strongly implicated in the pathogenesis of small intestinal damage induced by nonsteroidal anti-inflammatory drugs and other forms of ALI. ${ }^{9,11}$

Thus, we hypothesized that HMGB1 may be involved in ALI and lung inflammation, and its downstream TLR4, p38MAPK, and AP-1 signaling pathways may act as potentially important mediators in the development of ALI. In this study, a rat liver I/R injury model was used to induce ALI. The levels of serum and pulmonary HMGB1 were examined. To study the role of TLR4 and its downstream p38MAPK and AP-1 signaling pathways in the pathogenesis of liver I/R injury-induced ALI, TLR4-small hairpin RNA (shRNA) lentivirus were used to inhibit TLR4 expression in rat lung tissue.

\section{MATERIALS AND METHODS Ethics Statement}

All animal work was approved by the Animal Care and Use Committee of the Shanghai Jiaotong University School of Medicine. All animals received humane care in accordance with the guidelines for animal care published by the United States' National Institutes of Health (NIH) for animal care (Guide for the Care and Use of Laboratory Animals, Department of Health and Human Services, NIH Publication No. 86-23, revised 1985).

\section{ShRNA Lentivirus Vector of the TLR4 Gene}

ShRNA targeting Rattus norvegicus TLR4 gene (shTLR4; GenBank accession no.: NM_019178) and non-targeting shRNA (shNT) sequences were designed, chemically synthesized, and inserted into the pGCSIL-GFP by Shanghai Genechem Co. Ltd (Shanghai, China). The targeted sequences of TLR4 and non-targeting negative control were $5^{\prime}$-AACCTAGAACATGTGGATCTT- ${ }^{\prime}$ and $5^{\prime}$-TTCTCCGAA CGTGTCACGT- $3^{\prime}$, respectively. Then, the recombinant virus was packaged using Lentivector Expression Systems (Shanghai GeneChem Co. Ltd). The correct clone was identified by AgeI and EcoRI restriction digestion and sequenced.

\section{Experimental Animals and Groups}

Transfection efficiency of lentivirus was investigated by bioluminescence imaging, and best transfection efficiencies were observed at 20 days after lentivirus infection (data not shown). In this study, a total of 36 male Sprague-Dawley rats (180-220 g), purchased from Sino-British SIPPR/BK Lab (Shanghai, China), were randomly divided into six groups ( $n=6$ per group):

- Control group (Group Control): Animals in this group were administered with $0.25 \mathrm{ml}$ normal saline (NS) through intratracheal injection and received sham operation 20 days later.

- Liver I/R injury group (Group I/R): Animals in this group were administered with $0.25 \mathrm{ml}$ NS through intratracheal injection and received liver I/R injury operation 20 days later.

- Negative control group (Group shNT): These animals were infected with $0.25 \mathrm{ml}$ NS solution containing $1 \times 10^{8} \mathrm{TU}$ negative control shRNA lentivirus through intratracheal injection and received sham operation 20 days later.

- Positive control group (Group shNT+I/R): These animals were infected with $0.25 \mathrm{ml}$ NS solution containing $1 \times 10^{8} \mathrm{TU}$ negative control shRNA lentivirus through intratracheal injection and received liver I/R injury treatment 20 days later.

- TLR4 inhibition group (Group shTLR4): Animals in this group were infected with $0.25 \mathrm{ml}$ NS solution containing $1 \times 10^{8}$ TU TLR4-shRNA lentivirus through intratracheal injection and received a sham operation 20 days later.

- TLR4 inhibition group with liver I/R injury treatment (Group shTLR $4+I / R)$ : Animals in this group were infected with $0.25 \mathrm{ml}$ NS solution containing $1 \times 10^{8}$ TU TLR4-shRNA lentivirus through intratracheal injection and received liver $\mathrm{I} / \mathrm{R}$ injury treatment 20 days later.

\section{Liver I/R Injury Model}

Liver $\mathrm{I} / \mathrm{R}$ injury were performed according to the method described by Yamamoto et al ${ }^{28}$ with minor modification. Briefly, rats were anesthetized with pentobarbital sodium $(100 \mathrm{mg} / \mathrm{kg})$ and the depth of anesthesia was checked by monitoring the pedal withdrawal reflexes and the corneal reflex. When the mouse was sufficiently anesthetized, a $2-\mathrm{cm}$ midline abdominal incision was made. Vascular structures to the left and median lobe liver were identified and clamped for $90 \mathrm{~min}$ using a vascular clamp. After $90 \mathrm{~min}$ of warm ischemia, the clamps were removed to allow reperfusion for $18 \mathrm{~h}$. The rats received approximately $5 \mathrm{ml}$ of NS intraperitoneally before closure of the incision. ${ }^{6,7,29}$ And, the rats were allowed to regain consciousness during 
reperfusion period. The sham procedure was performed identically without vascular occlusion.

\section{Arterial Blood Gas Measurements}

As a physiologic measure of lung function, gas exchange was calculated as $\mathrm{PaO}_{2} / \mathrm{FiO}_{2}\left(\mathrm{P} / \mathrm{F}\right.$ ratio), where $\mathrm{PaO}_{2}$ is the partial pressure of oxygen in the arterial blood and $\mathrm{FiO}_{2}$ is the fraction of inspired oxygen and is equal to $21 \%$ by experimental design. Briefly, the rats were sufficiently anesthetized and breathing spontaneously of room air at baseline and $18 \mathrm{~h}$ after liver reperfusion. Then, the arterial blood was obtained $(0.3 \mathrm{ml})$ in heparinized syringes from femoral artery. To get $\mathrm{PaO}_{2}$ values, the sample was measured with a GEM Premier 3000 gas analyzer (Instrumentation Laboratory, Milan, Italy) immediately.

\section{Histopathological Analysis}

Changes in the lung tissue were examined morphologically as described previously. ${ }^{23}$ Briefly, the lung tissue were immersed in a $4 \%$ solution of paraformaldehyde in PBS and were fixed for $24 \mathrm{~h}$. Sections of $6 \mu \mathrm{m}$ thick were cut, deparaffinized, rehydrated, and stained with hematoxylin and eosin. The degree of microscopic injury was graded on a scale of $0-4$ (0, absent and appears normal; 1, light; 2, moderate; 3 , strong; 4, intense) for interstitial edema and neutrophil infiltration. $^{12}$ Moreover, a total lung injury score was calculated as the sum of the two components (three sections from each lung). Evaluations were performed by a pathologist blind to experimental groups using an Olympus CH30 microscope.

\section{Enzyme-Linked Immunosorbent Assay}

The levels of serum HMGB1 were measured with commercial HMGB1 Enzyme-Linked Immunosorbent Assay (ELISA) Kit П (Type B; Shino-Test Corporation, Tokyo, Japan). Blood samples $(1 \mathrm{ml})$ were collected from femoral artery before liver ischemia and $18 \mathrm{~h}$ after liver reperfusion, and centrifuged at $3000 \mathrm{~g}$ for $10 \mathrm{~min}$ at $4{ }^{\circ} \mathrm{C}$ to collect serum. The serum was kept at $-80{ }^{\circ} \mathrm{C}$ until analyzed.

The levels of IL- $1 \beta$ in the lung tissue were measured with commercial ELISA kits (R\&D Systems, Minneapolis, MN, USA). Lung tissue were perfused with ice-cold PBS at $18 \mathrm{~h}$ after liver $\mathrm{I} / \mathrm{R}$ injury and washed three times in PBS, homogenized, centrifuged at $11000 \mathrm{~g}$ at $4{ }^{\circ} \mathrm{C}$ for $15 \mathrm{~min}$, and the supernatant was obtained. The supernatant fraction was kept at $-80^{\circ} \mathrm{C}$ until analyzed. Before ELISA analysis, protein was quantified with a BCA Protein Assay Kit (Tiangen, Beijing, China).

\section{Western Blot Analysis}

Protein extraction and concentration determination were the same as described in ELISA. Samples of $30 \mu \mathrm{g}$ were run on $10 \%$ SDS-PAGE. The proteins were then electrotransferred onto nitrocellulose filter membranes. The membranes were incubated in PBS containing 5\% non-fat dry milk for $4 \mathrm{~h}$ at $25^{\circ} \mathrm{C}$. The blots were then incubated for $2 \mathrm{~h}$ at $25^{\circ} \mathrm{C}$ with primary antibodies for HMGB1 (1:500; Abcam, USA), TLR4 (1:1000; Cell Signaling Technology, USA), phospho-p38 (1:1000, Abcam) or $\beta$-actin (1:500; Epitomics, USA), and then incubated with IRDye $800 \mathrm{CW}$-conjugated goat antirabbit secondary antibody (1:5000; Rockland, USA) for $1 \mathrm{~h}$ at $25^{\circ} \mathrm{C}$. The infrared fluorescence image was obtained using Odyssey infrared imaging system (Li-Cor Bioscience, Lincoln, NE, USA), and the bands were quantified using imagePro Plus 5.1 software. Experiments were repeated at least three times and the relative expression of the target protein was normalized to the level of $\beta$-actin in the same sample.

\section{Real-Time Quantitative PCR Analysis}

Total RNA was extracted from the lung tissue $(n=6$ each group) using the TRIzol method (Invitrogen, Carlsbad, CA, USA). With the use of $1 \mu \mathrm{g}$ total RNA, the first strand of cDNA was synthesized by the AMV enzyme in a $20-\mu$ l reaction mixture (Takara, Otsu, Japan). Utilizing $2 \mu \mathrm{l}$ of reverse transcriptase products, real-time quantitative PCR was performed in a final volume of $20 \mu \mathrm{l}$ using the gene-specific primers. The following primers designed with Primer Express Software were used: rat HMGB1-5'-TCCCCTACTAAAGAC CTGAGAATG- $3^{\prime}$ (sense) and $5^{\prime}$-TTTATCCGCTTTCCTTGT ATCTG- $3^{\prime}$ (antisense); rat TLR4- $5^{\prime}$-CAGGGAGCACGAGG CTTCTAACC- $3^{\prime}$ (sense) and $5^{\prime}$-CTTGTGCCCTGTGAGGTC GTTGA-3' (antisense); and rat GAPDH- $5^{\prime}$-AGACCTCTAT GCCAACACAGTGC- $3^{\prime}$ (sense) and 5'-GAGCCACCAATCCA CACAGAGT- $3^{\prime}$ (antisense). Amplification was processed as follows: $95^{\circ} \mathrm{C}, 30 \mathrm{~s}, 1$ cycle; $95^{\circ} \mathrm{C}, 3 \mathrm{~s}$ and $60^{\circ} \mathrm{C}$ (HMGB1) or $62{ }^{\circ} \mathrm{C}$ (TLR4), $30 \mathrm{~s}$ for 40 cycles, and then the melting curve was determined. Gene transcripts were quantified with SYBR Premix Ex Taq Kit (Takara). Data were calculated by the $2^{-\Delta \Delta C T}$ method and presented as fold change of transcripts for the HMGB1 and TLR4 gene in the lung tissue of other groups compared with sham-operated rats (defined as 1.0 -fold). Rat GAPDH was used as an internal control. The relative expression of the target gene was normalized to the level of GAPDH in the same cDNA.

\section{Electrophoretic Mobility Shift Assay}

Nuclear extracts of the lung tissue were prepared with the Pierce Nuclear and Cytoplasmic Extraction Reagent Kit (Pierce) according to the manufacturer's instructions and quantified using the BCA kit (Pierce). Electrophoretic mobility shift assay (EMSA) was performed as described previously with minor modification. ${ }^{23}$ In brief, the AP-1 consensus oligonucleotide probe (5'-CGCTTGATGACTCAG CCGGAA- ${ }^{\prime}$ ) was end-labeled with DIG (Roche Applied Science, Indianapolis, IN, USA). After incubation of the nuclear protein $(30 \mu \mathrm{g})$ with the DIG-labeled oligonucleotide probe, the DNA-protein complexes were resolved on an $8 \%$ non-denaturing polyacrylamide gel, electrophoresed, dried, and electrotransferred to nitrocellulose filter membranes. Chemiluminescence detection of DIG-labeled DNA-protein complexes on the nylon membranes was detected using 
Hyperfilm ECL (Amersham, GE Health Care, Piscataway, NJ, USA). A quantitative densitometric analysis was performed using Quantity One 4.4, and then normalized to the control group to determine the fold change.

\section{Statistical Analysis}

All values are expressed as means \pm s.d. Results of serum HMGB1 and P/F ratio were analyzed by paired Student's $t$-test. All the other results were analyzed by ANOVA, followed by Tukey's method. Two-sided $P<0.05$ was considered statistically significant.

\section{RESULTS}

\section{Expression of TLR4 in Lung Tissue}

To investigate TLR4 expression in the lung tissue, real-time quantitative PCR and western blot analysis were used to detect TLR4 mRNA and protein expression in the lung tissue at $18 \mathrm{~h}$ after operation, respectively $(n=6)$. Compared to lung tissue from the shNT group, TLR4 mRNA expression decreased significantly in the lung tissue from the shTLR4 group, which indicated a valid inhibition of TLR4 in the lung tissue by TLR4-shRNA lentivirus $(0.56 \pm 0.18 v s 1.04 \pm 0.29)$. At $18 \mathrm{~h}$ after operation, liver I/R injury significantly increased TLR4 mRNA expression in the lung tissue from I/R and shNT $+\mathrm{I} / \mathrm{R}$ groups compared to the control group. However, only a slight increase of TLR4 mRNA was observed in the lung tissue from shTLR4 $+\mathrm{I} / \mathrm{R}$ after liver I/R injury, and the increase was not significant. When compared to the shNT $+\mathrm{I} / \mathrm{R}$ group, the expression of TLR4 mRNA in the lung tissue from the shTLR4 $+\mathrm{I} / \mathrm{R}$ group were significantly lower (Figure 1a). Similar results were found in protein expression of TLR4 (Figure 1b).

\section{ALI and Lung Inflammatory Response after Liver I/R Injury}

To examine whether ALI was induced by liver I/R injury, we performed lung histological analysis at $18 \mathrm{~h}$ after operation ( $n=6$ in each group). As shown in Figure 2a, normal lung structure was found in the control group. Lung tissue from the $\mathrm{I} / \mathrm{R}$ group displayed a feature of lung injury, including alveolar septal thickening, interstitial edema, and vascular congestion, as well as a mild neutrophil infiltration in the interstitium. No pathological changes were observed in the lung tissue from rats of shNT and shTLR4 groups. While lung tissue from rats receiving shNT $+\mathrm{I} / \mathrm{R}$ treatment displayed similar injury compared to those from the I/R group, coadministration of shTLR4 markedly attenuated the liver I/R injury-induced pulmonary neutrophil infiltration and interstitial edema. As shown in Figure $2 \mathrm{~b}$, these results were also confirmed by histological scores.

$\mathrm{P} / \mathrm{F}$ ratio, one of the markers for lung injury, was determined at baseline and $18 \mathrm{~h}$ after operation (Figure 2c; $n=6$ in each group). All groups displayed normal $\mathrm{P} / \mathrm{F}$ ratio at baseline. Compared to baseline, $\mathrm{P} / \mathrm{F}$ ratios were significantly lower after liver $I / R$ injury in both $I / R$ and shNT $+\mathrm{I} / \mathrm{R}$ groups, whereas not found in the shTLR $4+\mathrm{I} / \mathrm{R}$ group.

In addition, the levels of IL- $1 \beta$ in the lung tissue were used to describe the extent of lung inflammatory response. Expression of IL- $1 \beta$ in the lung tissue from $I / R, s h N T+I / R$, and shTLR $4+\mathrm{I} / \mathrm{R}$ groups increased significantly $18 \mathrm{~h}$ after surgery. Interestingly, IL- $1 \beta$ in the lung tissue from the shTLR $4+\mathrm{I} / \mathrm{R}$ group displayed a lower level at $18 \mathrm{~h}$ after liver $\mathrm{I} / \mathrm{R}$ injury when compared to the shNT $+\mathrm{I} / \mathrm{R}$ group $(n=6$; Figure 2d).
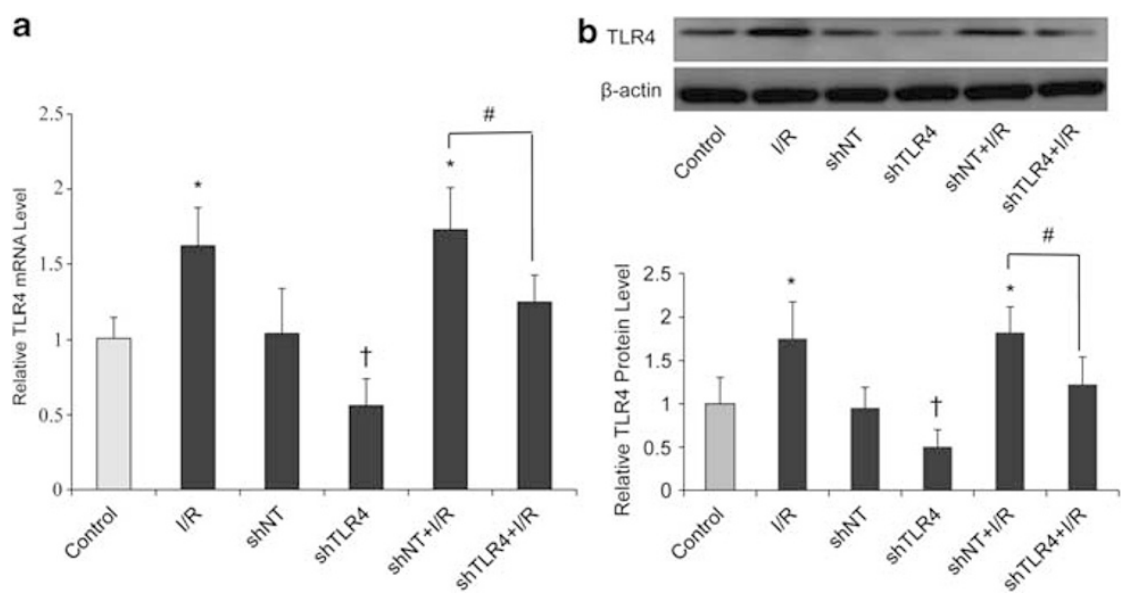

Figure 1 Expression of Toll-like receptor 4 (TLR4) in the lung tissue from rats at $18 \mathrm{~h}$ after liver ischemia/reperfusion (I/R) injury or sham operation. TLR4 mRNA (a, real-time PCR) and protein (b, western blot) expression levels in the lung tissue from rats at $18 \mathrm{~h}$ after liver $1 / \mathrm{R}$ injury or sham operation. ${ }^{*} P<0.05$ compared with the control group; ${ }^{\dagger} P<0.05$ compared with the non-targeting short hairpin RNA (shNT) group; ${ }^{*} P<0.05$ compared with the shNT + I/R group. Relative levels of TLR4 mRNA to the control group are normalized to glyceraldehyde 3-phosphate dehydrogenase (GAPDH), and relative levels of TLR4 protein to the control group are normalized to $\beta$-actin. Data are expressed as means \pm s.d.. Blots shown here are from a representative experiment repeated three times with similar results ( $n=6$ per group). Control, control group; I/R, liver I/R injury group; shNT, negative control group; shNT + I/R, positive control group; shTLR4, TLR4 inhibition group; shTLR4 + I/R, TLR4 inhibition group with liver I/R injury treatment. 
a

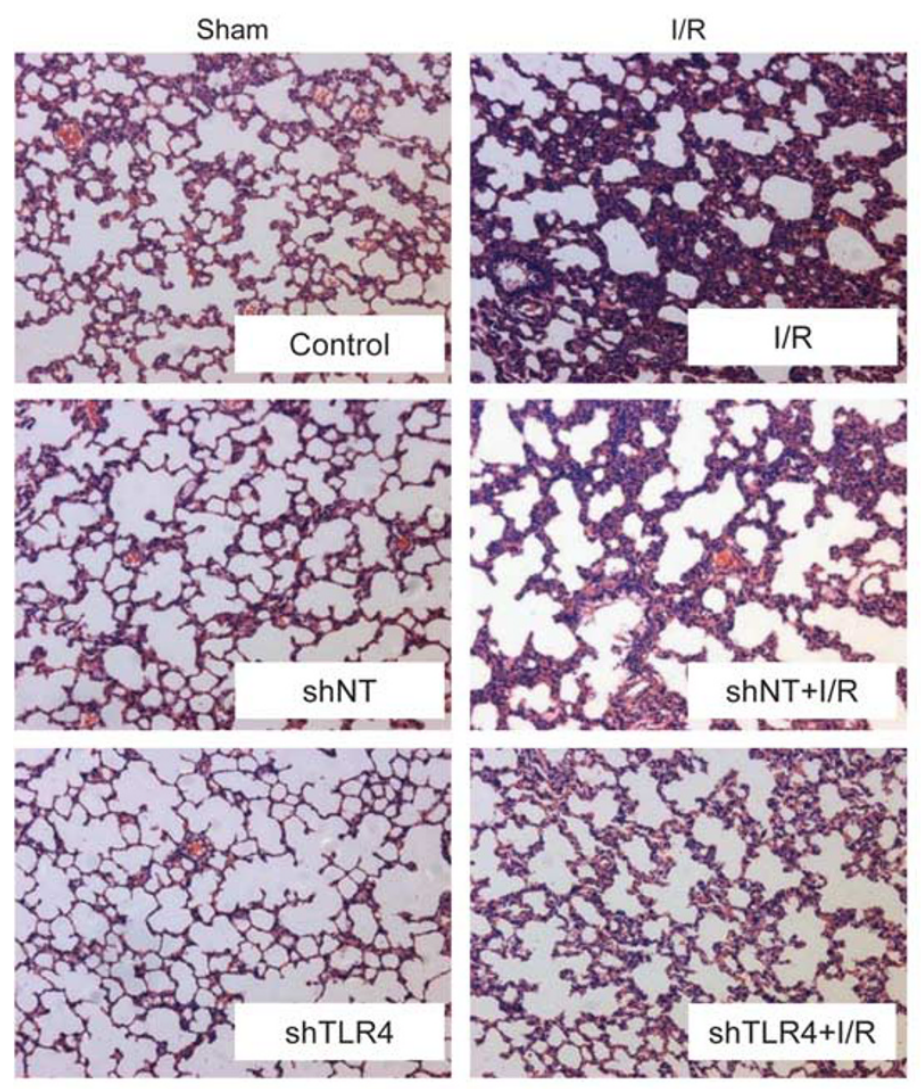

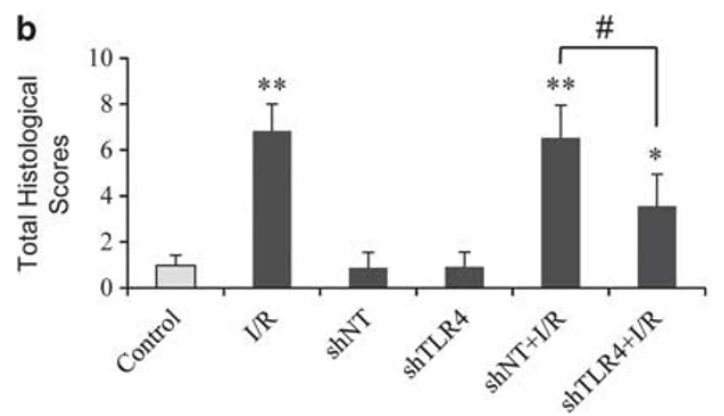
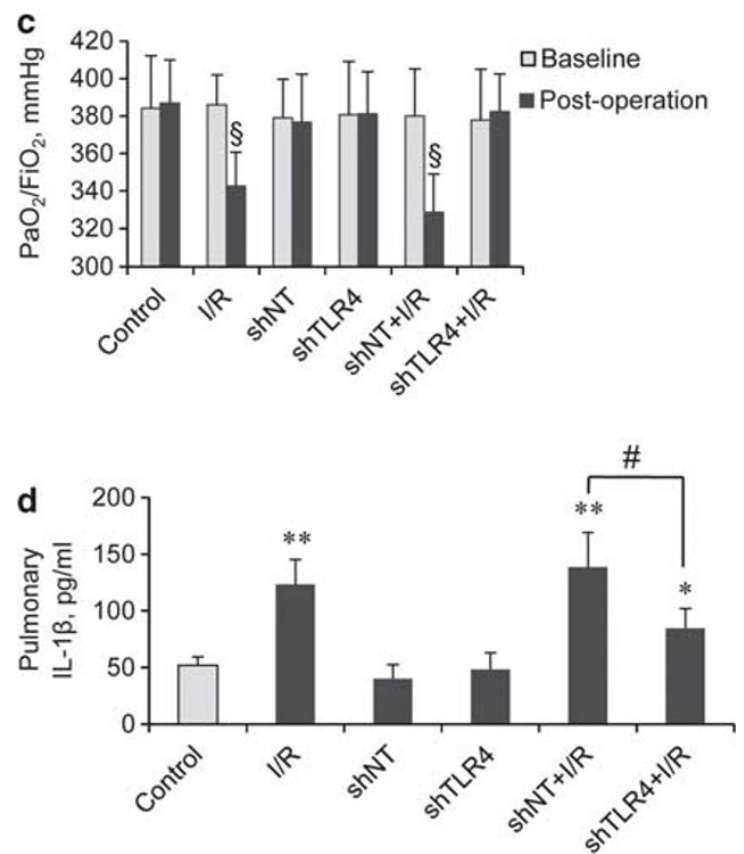

Figure 2 Acute lung injury and inflammation at $18 \mathrm{~h}$ after liver ischemia/reperfusion (I/R) injury or sham operation. (a) Morphological analysis of acute lung injury at $18 \mathrm{~h}$ after liver I/R injury $(\times 100)$; (b) changes in lung histological scores; $(\mathbf{c}) \mathrm{PaO}_{2} / \mathrm{FiO}_{2}(\mathrm{P} / \mathrm{F})$ ratios were obtained at baseline and $18 \mathrm{~h}$ after liver I/R injury; (d) interleukin (IL)- $1 \beta$ levels in the lung tissue from rats at $18 \mathrm{~h}$ after liver I/R injury. ${ }^{*} P<0.05$, ${ }^{*} P<0.01$ compared to the control group; ${ }^{P} P<0.05$ compared to non-targeting short hairpin RNA (shNT) + I/R group; ${ }^{\S} P<0.05$ compared to baseline. Data are expressed as means \pm s.d. ( $n=6$ per group). Control, control group; I/R, liver I/R injury group; shNT, negative control group; shNT + I/R, positive control group; shTLR4, TLR4 inhibition group; shTLR4 + I/R, TLR4 inhibition group with liver I/R injury treatment.

\section{Liver I/R Injury Increased Serum and Lung HMGB1 Levels}

To investigate whether HMGB1 was released to the serum after liver I/R injury, serum HMGB1 levels were measured (Figure 3a, $n=6$ ). At baseline, there were no significant differences among these groups. Serum HMGB1 levels in I/R, shNT $+\mathrm{I} / \mathrm{R}$, and shTLR4 $+\mathrm{I} / \mathrm{R}$ groups increased significantly at $18 \mathrm{~h}$ after liver $\mathrm{I} / \mathrm{R}$ injury when compared to its corresponding baseline. And, no significant differences were found between shNT $+\mathrm{I} / \mathrm{R}$ and shTLR $4+\mathrm{I} / \mathrm{R}$ groups after liver I/R injury. Sham operation did not increase serum HMGB1 levels in control, shNT, and shTLR4 groups.

We also examined relative mRNA and protein expression of HMGB1 in the lung tissue. As is shown in Figure 3b, relative levels of HMGB1 mRNA in the lung tissue from $\mathrm{I} / \mathrm{R}$, shNT $+\mathrm{I} / \mathrm{R}$, and shTLR4 $+\mathrm{I} / \mathrm{R}$ groups increased significantly at $18 \mathrm{~h}$ after liver $\mathrm{I} / \mathrm{R}$ injury when compared to the control group, respectively. Western blot analysis showed that protein levels of HMGB1 in the lung tissue at $18 \mathrm{~h}$ after operation were in parallel with mRNA expression (Figure 3c). Both mRNA and protein levels of HMGB1 in the lung tissue were similar between shNT + I/R and shTLR4 + I/R groups.

\section{Expression of Phospho-P38 in Lung Tissue}

Relative expression of phospho-p38 in lung tissues at $18 \mathrm{~h}$ after operation was also measured by western blot analysis (Figure 4a). Compared to the control group, protein levels of phospho-p38 in the lung tissue from I/R and shNT $+\mathrm{I} / \mathrm{R}$ groups increased significantly. However, only a slight increase of phospho-p38 was observed in the lung tissue from shTLR4 + I/R after liver I/R injury, and the increase was not significant when compared to the control group. In addition, the expression of phospho-p38 protein in the lung tissue 

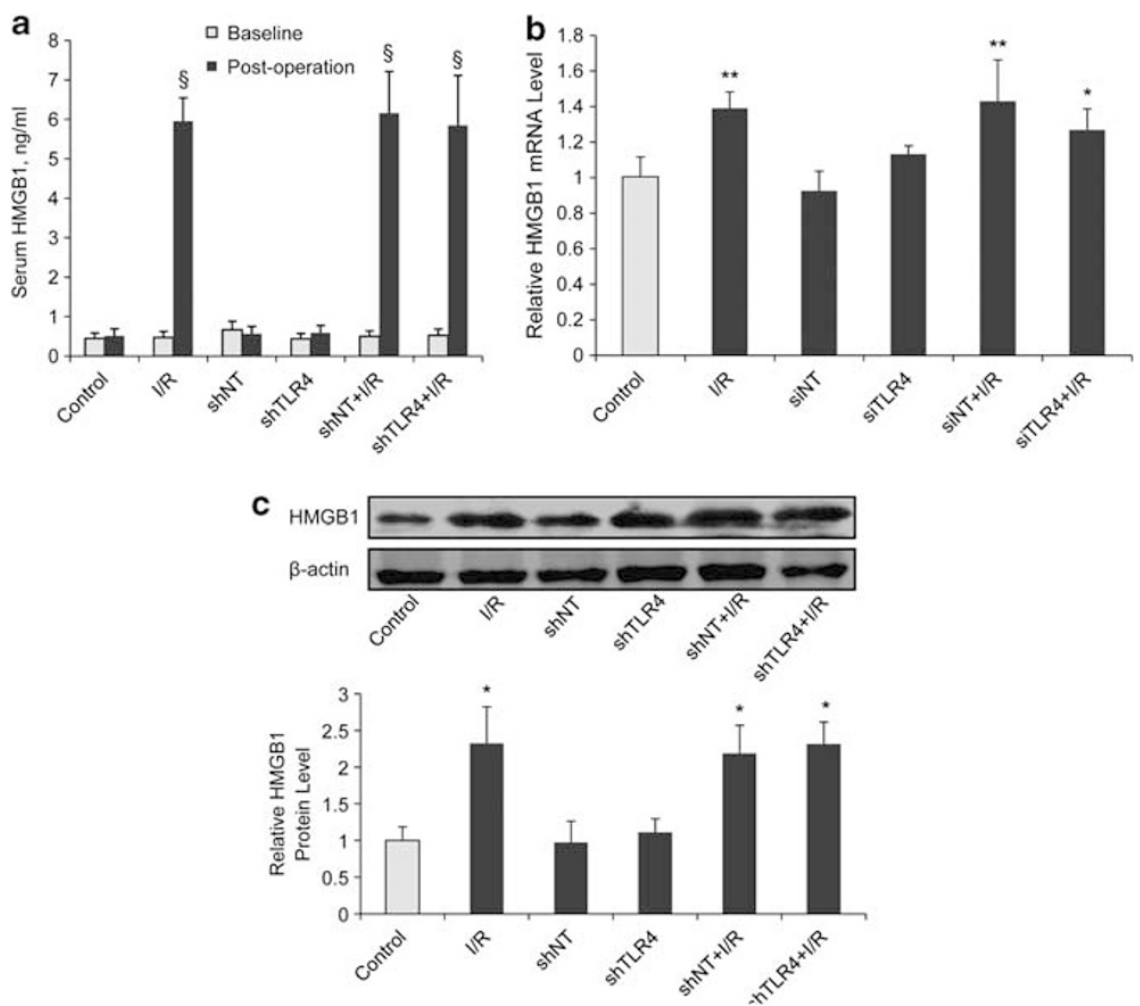

Figure 3 Expression of high-mobility group box protein 1 (HMGB1) in serum and lung tissue from rats at $18 \mathrm{~h}$ after liver ischemia/reperfusion (I/R) injury or sham operation. Serum HMGB1 levels at baseline and $18 \mathrm{~h}$ after liver I/R injury (a); relative mRNA (b) and protein (c, western blot) expression in the lung tissue at $18 \mathrm{~h}$ after liver I/R injury were determined by real-time quantitative polymerase chain reaction (PCR) and western blot, respectively. ${ }^{*} P<0.05,{ }^{* *} P<0.01$ compared to the control group; ${ }^{\S} P<0.01$ compared to baseline. Relative levels of HMGB1 mRNA to the control group are normalized to glyceraldehyde 3-phosphate dehydrogenase (GAPDH), and relative levels of HMGB1 protein to the control group are normalized to $\beta$-actin. Data are expressed as means \pm s.d. Blots shown here are from a representative experiment repeated three times with similar results $(n=6$ per group). Control, control group; I/R, liver I/R injury group; shNT, negative control group; shNT + I/R, positive control group; shTLR4, TLR4 inhibition group; shTLR4 + I/R, TLR4 inhibition group with liver I/R injury treatment.

\section{a}
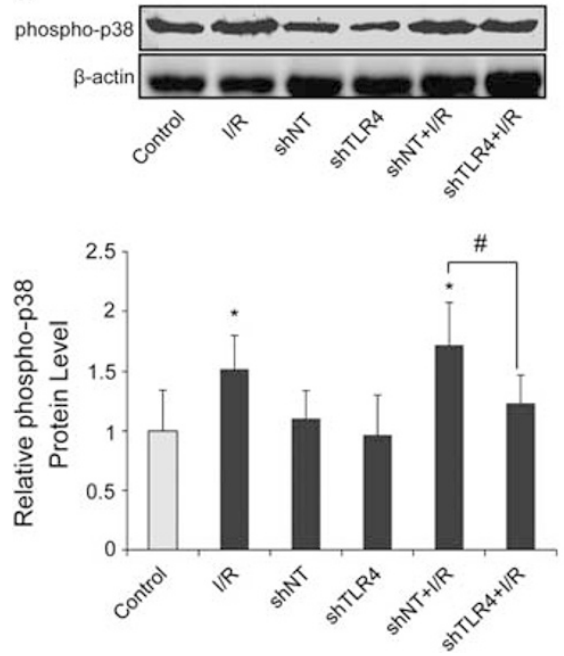

\section{b}

AP-1
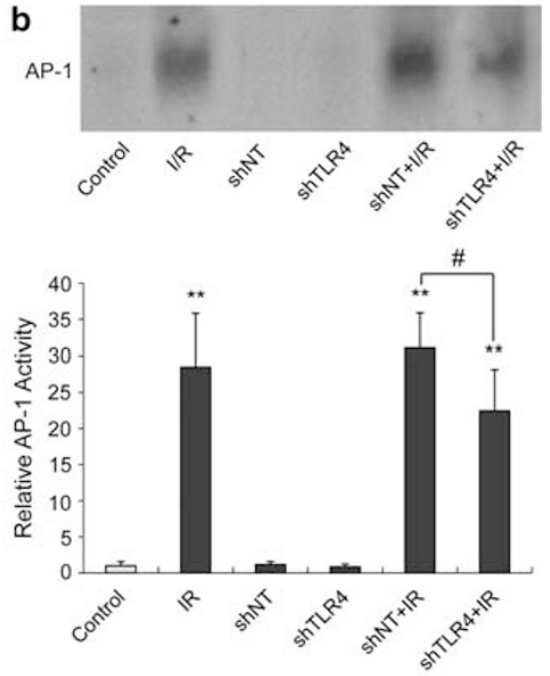

Figure 4 Activation of p38 mitogen-activated protein kinase (p38MAPK) and activator protein-1 (AP-1) in the lung tissue from rats at $18 \mathrm{~h}$ after liver ischemia/reperfusion (I/R) injury or sham operation. (a) Expression of phospho-p38 in the lung tissue from rats at $18 \mathrm{~h}$ after liver $\mathrm{I} / \mathrm{R}$ injury was determined by western blot. Relative levels of phospho-p38 protein to the control group are normalized to $\beta$-actin. Blots shown here are from a representative experiment repeated three times with similar results. (b) AP-1 activity was evaluated with electrophoretic mobility shift assay (EMSA) with representative image shown. ${ }^{*} P<0.05,{ }^{*} P<0.01$ compared to the control group; ${ }^{\#} P<0.05$ compared to the shNT $+\mathrm{I} / \mathrm{R}$ group. Data are expressed as means \pm s.d. ( $n=6$ per group). Control, control group; I/R, iver I/R injury group; shNT, negative control group; shNT $+\mathrm{I} / \mathrm{R}$, positive control group; shTLR4, TLR4 inhibition group; shTLR4 + I/R, TLR4 inhibition group with liver I/R injury treatment. 
from the shTLR $4+\mathrm{I} / \mathrm{R}$ group were significantly lower when compared to the shNT $+\mathrm{I} / \mathrm{R}$ group.

\section{Liver I/R Injury Induced Activation of AP-1}

The results from EMSA showed that AP-1 activity was low in nuclear extracts of lung tissues from control, shNT, and shTLR4 rats. AP-1 activity increased significantly in the I/R group, shNT $+\mathrm{I} / \mathrm{R}$ group, and shTLR $4+\mathrm{I} / \mathrm{R}$ group when compared to the control group. Compared to the shNT $+\mathrm{I} / \mathrm{R}$ group, AP-1 was less activated in the lung tissue from the shTLR4 + I/R group (Figure $4 \mathrm{~b}$ ).

\section{DISCUSSION}

ALI and ARDS are common complications after liver transplantation and after major liver surgery, and thereby significantly contribute to perioperative morbidity and mortality. ${ }^{1,2}$ This form of lung injury has been attributed to hepatic I/R injury, but the underlying mechanisms have not been fully elucidated. ${ }^{3-5}$ The aim of this study was to investigate whether HMGB1 was involved as a stimulating factor, and whether TLR4, p38MAPK, and AP-1 signaling pathways act as mediators in the development of liver $I / R$ injury induced ALI. We found that levels of serum and lung HMGB1 increased significantly after liver I/R injury; that TLR4, p38MAPK, and AP-1 signaling pathways were activated in the pathologic process of liver $I / R$ injuryinduced ALI; and that ALI and lung inflammatory response can be attenuated by knockdown of TLR4 in the lung tissue. These results suggest that HMGB1 might be involved as a stimulating factor in liver I/R injury-induced ALI, and its downstream TLR4, p38MAPK, and AP-1 signaling pathways mediate this form of ALI.

To investigate whether liver I/R injury can induce lung inflammatory response and ALI, we used a classical rat liver I/R injury model. Features characteristic of lung injury were found after liver I/R injury by histological analysis, which was also confirmed by significantly decreased $\mathrm{P} / \mathrm{F}$ ratios. Pulmonary levels of IL- $1 \beta$ were also significantly higher after liver I/R injury compared to the control group, which indicated lung inflammatory response. Similar results were found in previous studies; liver I/R injury induced lung edema, pulmonary neutrophil accumulation, and inflammatory chemokine expression. ${ }^{3,4,30}$ In this study, P/F ratio was used as an index to characterize the ALI, and has not been reported previously. As stated above, our findings strongly suggested that liver I/R injury would ultimately lead to lung inflammatory response and ALI.

It has been demonstrated that liver I/R injury results in the activation of several inflammatory pathways, such as those for free radicals, cytokines, and neutrophil-mediated tissue damage. ${ }^{31}$ The lung is frequently damaged by proinflammatory mediators released from the injured liver after liver IR, as the lungs are the first capillary bed that is reached by the blood after leaving the hepatic circulation. ${ }^{3-7}$ HMGB1 was recently found to act as a potent proinflammatory cytokine and participated in the development of systemic inflammatory response, when it was released into the extracellular environment. ${ }^{32,33}$ HMGB1 was also found to be involved in many other types of ALI, such as endotoxin, ventilator, and hemorrhage-induced ALI. ${ }^{10-12}$ Interestingly, HMGB1 was reported to rapidly mobilize and release into system circulation from damaged liver in the setting of liver I/R injury. ${ }^{34,35}$ Previous studies also demonstrated that serum HMGB1 level remained elevated until $12 \mathrm{~h}$ after reperfusion, and that the removal of excessive serum HMGB1 with adsorption column improved the lung injury score. ${ }^{28}$ Whether or not HMGB1 was transported to the lung and whether downstream signaling pathways in lung were activated was not investigated. In this study, similar results were obtained; serum HMGB1 increased significantly after liver I/R injury. More importantly, HMGB1 protein was found to be significantly higher in the lung tissue, which suggests that HMGB1 might be transported to lung tissue by systemic circulation. In addition, HMGB1 was reported to be released from macrophages and monocytes after exposure to proinflammatory cytokines. ${ }^{36-39}$ Given that proinflammatory cytokines might be transported to lung tissue after liver I/R injury, ${ }^{3-7}$ lung cells might be activated by proinflammatory cytokines and then release HMGB1. ${ }^{40,41}$ For this reason, we examined HMGB1 mRNA in the lung tissue, and found that HMGB1 mRNA was significantly increased in the lung tissue after liver I/R injury. These results suggest that HMGB1, both released passively from damaged liver and actively from lung cells, might be involved in activating lung inflammatory response in liver I/R injury-induced ALI. Future experiments using an HMGB1-neutralizing antibody may help reveal its role in liver I/R injury-induced ALI.

The Toll-like receptor family is one of the best-characterized pattern recognition receptor families and is responsible for sensing invading pathogens. HMGB1 activates inflammatory pathways by stimulating TLR4 in many types of tissue injuries. ${ }^{42,43}$ Our previous work, ${ }^{22-24}$ as well as the work of others, ${ }^{25-27}$ indicated that TLR4 mediates many forms of ALI, such as hemorrhagic shock-induced ALI and LPS-induced ALI. Overexpression of TLR4 in the lung tissue amplifies the severity of LPS-induced ALI. In this study, TLR4 mRNA and protein expression increased significantly in the lung tissue $18 \mathrm{~h}$ after liver I/R injury. Interestingly, liver $\mathrm{I} / \mathrm{R}$ injury-induced lung damage, decrease of $\mathrm{P} / \mathrm{F}$ ratio, and lung inflammatory response were significantly attenuated by knockdown of pulmonary TLR4. To our knowledge, this is the first time to report that TLR4 was involved in the pathogenesis of liver I/R injury-induced ALI.

We further investigated whether pulmonary TLR4 activation leads to activation of its downstream p38MAPK and AP-1 signaling pathways, which are considered to be important in regulating inflammatory response. ${ }^{15,16}$ In this work, activation of p38MAPK in the lung tissue enhanced significantly after liver I/R injury, and the increases were inhibited by TLR4 knockdown, which implies that p38MAPK 
signaling pathway might contribute to liver I/R injuryinduced ALI. Activation of AP-1 in the lung tissue also increased after liver I/R injury, which was suppressed by TLR4 knockdown, indicating the involvement of AP-1 in TLR4-mediated lung inflammation after liver I/R injury. Activation of p38MAPK by TLR4 was reported to upregulate the inflammation-related genes and stimulated the release of IL-6, TNF, CXCL2, and CXCL10 protein in the lungs. ${ }^{40}$ TLR4 mediated-activation of p38MAPK was also contributed to HMGB1-induced human lung endothelial cell cytoskeletal rearrangement and barrier disruption. ${ }^{41}$ Moreover, AP-1 is a critical transcription factor required for the expression of many cytokines involved in the pathogenesis of ALI. ${ }^{23,44}$ Considering the roles of HMGB1, TLR4, p38MAPK, and AP-1 signaling pathways in ALI and lung inflammation, our findings implicated $\mathrm{p} 38 \mathrm{MAPK}$ and AP-1 signaling pathways as potentially important mediators of the classic TLR4/ MyD88 signal-transduction pathways involved in lung inflammatory injury after liver $\mathrm{I} / \mathrm{R}$ injury. In addition, activation of TLR4 can also activate other intracellular signaling systems, including the extracellular signal-regulated kinase (ERK), c-Jun NH2-terminal kinase (JNK), as well as the nuclear factor $\mathrm{kB}(\mathrm{NF}-\kappa \mathrm{B})$ pathways, all of which are pivotal regulators of inflammatory immune responses and cell survival and death. ${ }^{45}$ Furthermore, studies are needed to investigate the involvements of ERK, JNK, and NF- $\kappa \mathrm{B}$ in liver I/R injury-induced ALI.

In conclusion, our study suggests that HMGB1 might be a stimulating factor in liver I/R injury-induced ALI, and that its downstream TLR4, p38MAPK, and AP-1 signaling pathways are potentially important mediators in the development of ALI. Thus, blocking HMGB1 or inhibiting TLR4, p38MAPK, and AP-1 signaling pathways may be a useful therapeutic option against liver I/R injury-induced ALI.

\section{ACKNOWLEDGEMENTS}

This research was supported by a grant from the Science and Technology Commission of Shanghai Municipality Foundation (No. 10411951600), grants from the National Natural Science Foundation of China (NSFC) (No. 81000025 and 81170062), a grant from Specialized Research Fund for the Doctoral Program of Higher Education (No. 20110073110073), and a grant from Doctorate Foundation of Shanghai Jiaotong University School of Medicine (No. BXJ201120).

\section{DISCLOSURE/CONFLICT OF INTEREST}

The authors declare no conflict of interest.

1. Hong SK, Hwang S, Lee SG, et al. Pulmonary complications following adult liver transplantation. Transplant Proc 2006;38:2979-2981.

2. Bozbas SS, Eyuboglu FO, Ozturk Ergur F, et al. Pulmonary complications and mortality after liver transplant. Exp Clin transplant 2008;6:264-270.

3. Glasgow SC, Ramachandran S, Csontos KA, et al. Interleukin-1 beta is prominent in the early pulmonary inflammatory response after hepatic injury. Surgery 2005;138:64-70.

4. Franco-Gou R, Rosello-Catafau J, Peralta C. Protection against lung damage in reduced-size liver transplantation. Crit Care Med 2006;34:1506-1513.
5. Hirsch J, Niemann CU, Hansen KC, et al. Alterations in the proteome of pulmonary alveolar type II cells in the rat after hepatic ischemiareperfusion. Crit Care Med 2008;36:1846-1854.

6. Saidi RF, Chang J, Brooks S, et al. Ischemic preconditioning and intermittent clamping increase the tolerance of fatty liver to hepatic ischemia-reperfusion injury in the rat. Transplant Proc 2007;39: 3010-3014.

7. Choi S, Noh J, Hirose R, et al. Mild hypothermia provides significant protection against ischemia/reperfusion injury in livers of obese and lean rats. Ann Surg 2005;241:470-476.

8. Lotze MT, Zeh HJ, Rubartelli A, et al. The grateful dead: damageassociated molecular pattern molecules and reduction/oxidation regulate immunity. Immunol Rev 2007;220:60-81.

9. Nadatani $Y$, Watanabe $T$, Tanigawa $T$, et al. High mobility group box 1 promotes small intestinal damage induced by nonsteroidal antiinflammatory drugs through toll-like receptor 4. Am J Pathol 2012;181:98-110.

10. Ogawa EN, Ishizaka A, Tasaka $\mathrm{S}$, et al. Contribution of high-mobility group box-1 to the development of ventilator-induced lung injury. Am J Respir Crit Care Med 2006;174:400-407.

11. Kim JY, Park JS, Strassheim D, et al. HMGB1 contributes to the development of acute lung injury after hemorrhage. Am J Physiol Lung Cell Mol Physiol 2005;288:L958-965.

12. Hagiwara $S$, Iwasaka $H$, Hasegawa $A$, et al. Effects of hyperglycemia and insulin therapy on high mobility group box 1 in endotoxininduced acute lung injury in a rat model. Crit Care Med 2008;36: 2407-2413.

13. Hori O, Brett J, Slattery $\mathrm{T}$, et al. The receptor for advanced glycation end products (RAGE) is a cellular binding site for amphoterin. Mediation of neurite outgrowth and co-expression of rage and amphoterin in the developing nervous system. J Biol Chem 1995;270:25752-25761.

14. Park JS, Svetkauskaite $D, H e ~ Q$, et al. Involvement of toll-like receptors 2 and 4 in cellular activation by high mobility group box 1 protein. J Biol Chem 2004;279:7370-7377.

15. Wang C, Deng L, Hong M, et al. TAK1 is a ubiquitin-dependent kinase of MKK and IKK. Nature 2001:412:346-351.

16. Sato $\mathrm{S}$, Sanjo $\mathrm{H}$, Takeda $\mathrm{K}$, et al. Essential function for the kinase TAK1 in innate and adaptive immune responses. Nat Immunol 2005;6: 1087-1095.

17. Wheeler AP, Bernard GR. Acute lung injury and the acute respiratory distress syndrome: a clinical review. Lancet 2007;369:1553-1564.

18. Abraham E, Carmody A, Shenkar R, Arcaroli J. Neutrophils as early immunologic effectors in hemorrhage- or endotoxemia-induced acute lung injury. Am J Physiol Lung Cell Mol Physiol 2000;279:L1137-1145.

19. Andonegui G, Bonder CS, Green F, et al. Endothelium-derived Toll-like receptor-4 is the key molecule in LPS-induced neutrophil sequestration into lungs. J Clin Invest 2003;111:1011-1020.

20. Guillot L, Medjane S, Le-Barillec K, et al. Response of human pulmonary epithelial cells to lipopolysaccharide involves Toll-like receptor 4 (TLR4)-dependent signaling pathways: evidence for an intracellular compartmentalization of TLR4. J Biol Chem 2004;279:2712-2718.

21. Sha $Q$, Truong-Tran $A Q$, Plitt JR, et al. Activation of airway epithelial cells by toll-like receptor agonists. Am J Respir Cell Mol Biol 2004;31:358-364.

22. He $\mathrm{Z}$, Zhu $\mathrm{Y}$, Jiang $\mathrm{H}$. Inhibiting toll-like receptor 4 signaling ameliorates pulmonary fibrosis during acute lung injury induced by lipopolysaccharide: an experimental study. Respir Res 2009;10:126.

23. Tian J, Wang $Y$, He Z, et al. Hydroxyethyl starch ( $130 \mathrm{kD})$ inhibits Tolllike receptor 4 signaling pathways in rat lungs challenged with lipopolysaccharide. Anesth Analg 2011;113:112-119.

24. He Z, Gao Y, Deng Y, et al. Lipopolysaccharide induces lung fibroblast proliferation through Toll-like receptor 4 signaling and the phosphoinositide3-kinase-Akt pathway. PLoS One 2012;7:e35926.

25. Jeyaseelan S, Chu HW, Young SK, et al. Distinct roles of pattern recognition receptors CD14 and Toll-like receptor 4 in acute lung injury. Infect Immun 2005;73:1754-1763.

26. Lv T, Shen $X$, Shi $Y$, et al. TLR4 is essential in acute lung injury induced by unresuscitated hemorrhagic shock. J Trauma 2009;66:124-131.

27. Togbe D, Schnyder-Candrian S, Schnyder B, et al. TLR4 gene dosage contributes to endotoxin-induced acute respiratory inflammation. J Leukocyte Biol 2006;80:451-457. 
28. Yamamoto $\mathrm{T}$, Ono $\mathrm{T}$, Ito $\mathrm{T}$, et al. Hemoperfusion with a high-mobility group box 1 adsorption column can prevent the occurrence of hepatic ischemia-reperfusion injury in rats. Crit Care Med 2010;38: 879-885.

29. Saidi RF, Chang J, Verb S, et al. The effect of methylprednisolone on warm ischemia-reperfusion injury in the liver. Am J Surg 2007; 193:345-347, discussion 347-348.

30. Takeuchi D, Yoshidome $H$, Kurosawa $H$, et al. Interleukin-18 exacerbates pulmonary injury after hepatic ischemia/reperfusion in mice. J Surg Res 2010;158:87-93.

31. Ben DF, Yu XY, Ji GY, et al. TLR4 mediates lung injury and inflammation in intestinal ischemia-reperfusion. J Surg Res 2012;174:326-333.

32. Wang $\mathrm{H}$, Bloom $\mathrm{O}$, Zhang $\mathrm{M}$, et al. HMG-1 as a late mediator of endotoxin lethality in mice. Science 1999;285:248-251.

33. Scaffidi P, Misteli T, Bianchi ME. Release of chromatin protein HMGB1 by necrotic cells triggers inflammation. Nature 2002;418:191-195

34. Tsung A, Klune JR, Zhang X, et al. HMGB1 release induced by liver ischemia involves Toll-like receptor 4 dependent reactive oxygen species production and calcium-mediated signaling. J Exp Med 2007;204:2913-2923.

35. Dhupar R, Klune JR, Evankovich J, et al. Interferon regulatory factor 1 mediates acetylation and release of high mobility group box 1 from hepatocytes during murine liver ischemia-reperfusion injury. Shock 2011;35:293-301.

36. Lu B, Nakamura T, Inouye $\mathrm{K}$, et al. Novel role of PKR in inflammasome activation and HMGB1 release. Nature 2012;488:670-674.
37. Lamkanfi M, Sarkar A, Vande Walle L, et al. Inflammasome-dependent release of the alarmin HMGB1 in endotoxemia. J Immunol 2010; 185:4385-4392.

38. Andersson U, Tracey KJ. HMGB1 is a therapeutic target for sterile inflammation and infection. Ann Rev Immunol 2011;29:139-162.

39. Yang $\mathrm{H}$, Wang $\mathrm{H}, \mathrm{Czura} \mathrm{CJ}$, et al. The cytokine activity of HMGB1. J Leukocyte Biol 2005;78:1-8.

40. Barrenschee M, Lex D, Uhlig S. Effects of the TLR2 agonists MALP-2 and Pam3Cys in isolated mouse lungs. PLoS One 2010;5:e13889.

41. Wolfson RK, Chiang ET, Garcia JG. HMGB1 induces human lung endothelial cell cytoskeletal rearrangement and barrier disruption. Microvasc Res 2011;81:189-197.

42. Yang $\mathrm{H}$, Hreggvidsdottir HS, Palmblad $\mathrm{K}$, et al. A critical cysteine is required for HMGB1 binding to Toll-like receptor 4 and activation of macrophage cytokine release. Proc Natl Acad Sci USA 2010;107: 11942-11947.

43. Dobrovolskaia MA, Medvedev $A E$, Thomas $K E$, et al. Induction of in vitro reprogramming by Toll-like receptor (TLR) 2 and TLR4 agonists in murine macrophages: effects of TLR 'homotolerance' versus 'heterotolerance' on NF-kappa B signaling pathway components. J Immunol 2003;170:508-519.

44. Wang $\mathrm{F}$, Xia ZF, Chen $\mathrm{XL}$, et al. Angiotensin II type-1 recepto antagonist attenuates LPS-induced acute lung injury. Cytokine 2009;48:246-253.

45. Arumugam TV, Okun E, Tang SC, et al. Toll-like receptors in ischemiareperfusion injury. Shock 2009;32:4-16. 